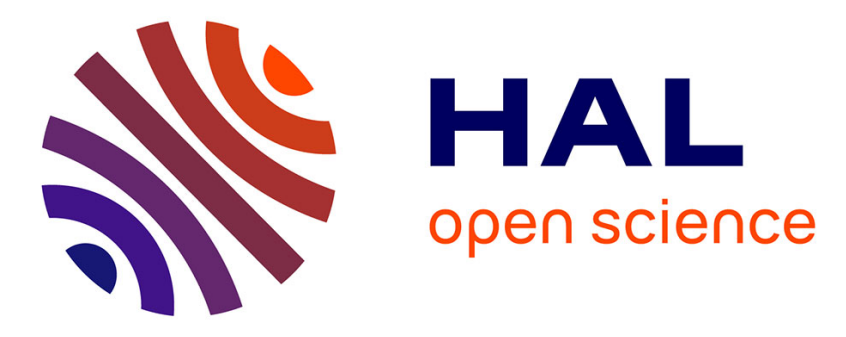

\title{
Introduction to chemical warfare agents, relevant simulants and modern neutralisation methods
}

Baptiste Picard, Isabelle Chataigner, Jacques Maddaluno, Julien Legros

\section{To cite this version:}

Baptiste Picard, Isabelle Chataigner, Jacques Maddaluno, Julien Legros. Introduction to chemical warfare agents, relevant simulants and modern neutralisation methods. Organic \& Biomolecular Chemistry, 2019, 17 (27), pp.6528-6537. 10.1039/c9ob00802k . hal-02996925

\section{HAL Id: hal-02996925 \\ https://hal.science/hal-02996925}

Submitted on 11 Nov 2020

HAL is a multi-disciplinary open access archive for the deposit and dissemination of scientific research documents, whether they are published or not. The documents may come from teaching and research institutions in France or abroad, or from public or private research centers.
L'archive ouverte pluridisciplinaire HAL, est destinée au dépôt et à la diffusion de documents scientifiques de niveau recherche, publiés ou non, émanant des établissements d'enseignement et de recherche français ou étrangers, des laboratoires publics ou privés. 


\section{ARTICLE}

\section{Introduction to chemical warfare agents, relevant simulants and modern neutralisation methods}

Received 00th January 20xx, Accepted 00th January 20xx DOI: $10.1039 / \times 0 \times x 00000 x$

\begin{abstract}
Baptiste Picard, ${ }^{\mathrm{a}}$ Isabelle Chataigner, ${ }^{\mathrm{a}, \mathrm{b}}$ Jacques Maddaluno, ${ }^{\mathrm{a}}$ and Julien Legros*a
Despite international prohibition, some ill-intentioned States and organisations have shown their will -and capacity- to run chemical weapons programs, and the number of incidents involving chemical warfare agents (CWA) has dramatically increased in recent years. This article intends to offer a clear overview to organic chemists not specialized in the field by 1 ) introducing the main CWAs and their relevant simulants legally usable in academic laboratories, 2) presenting a selection of recent and soft neutralisation methods, such as organocatalysis, metal-organic frameworks, polyoxometalates and continuous flow. These modern approaches offer potential future alternatives to "heavy" decontamination methods.
\end{abstract}

\section{Introduction}

The Chemical Weapons Convention (CWC) opened for signature in 1993 and entered into force in 1997 with the establishment of the Organisation for the Prohibition of Chemical Weapons (OPCW). In the meantime, Japan underwent terrorist attacks with nerve agent Sarin in Matsumoto and in Tokyo (1994 and 1995), which remain the last known usages of chemical warfare agents (CWA) of the last century. Whereas the CWC just celebrated its $20^{\text {th }}$ anniversary, the ongoing threat of CWA gained global visibility in 2017 with an assassination by means of VX in Kuala Lumpur. Multiple case of CWA utilization were reported during the Syrian conflict last years, and a murder attempt with a nondeclared nerve agent (from the so-called "Novichok" series) was conducted on the European soil, for the first time since the end of World War I, in Salisbury (UK) in March 2018. The CWC prohibits the synthesis of chemical warfare agents on a large scale and it restricts their use to protection and peaceful research studies. Unfortunately, not only chemical weapons are still being produced and used in the world, but also at a rate that seems to have accelerated in recent years, even if the disarmament process of the historically endowed States is almost complete. ${ }^{1}$ It is therefore sadly becoming essential to develop flexible scientific and technological methods for onsite sustainable neutralisation of chemical warfare agents under mild conditions.

\footnotetext{
${ }^{a .}$ Address here.

${ }^{b .}$ Address here.

c. Address here.

† Footnotes relating to the title and/or authors should appear here.

Electronic Supplementary Information (ESI) available: [details of any supplementary information available should be included here]. See DOI: $10.1039 / x 0 x \times 00000 x$
}

\section{Chemical weapons and chemical warfare agents}

Chemical weapons are defined in full-length in the Article II of the CWC. ${ }^{2}$ Beside this 3-page international text written by diplomats, military chemists simply name chemical weapon a toxic molecule coupled to a vectorization agent, whereas chemical warfare agent (CWA) refers to the toxic molecule; this latter term is used in the following. The CWC includes three schedules, each associated with legally binding obligations for the signatory countries. Molecules directly usable as CWA and having no peaceful purpose are listed in Schedule 1-Subdivision A. Acquisition/holding/use of these CWA are therefore strictly controlled and this review focuses only on these chemicals (Scheme 1 and Table 1).

\subsection{Main CWA}

Organoarsenic derivatives (lewisites, clarks,...) were widely used during World War I, but they now fortunately belong to history and no use have been reported for decades. ${ }^{3}$ Saxitoxin ${ }^{4}$ and the glycoprotein ricin $^{5}$ are natural compounds synthesized by animal and plant organisms, respectively, extracted in very small quantities and are at the border of biological warfare agents. The main current chemical threat concerns easily synthesized agents potentially manufacturable on large scale: nitrogen $^{6}$ and sulfur $^{7}$ mustards (e.g. yperite) and organophosphorus nerve agents (OPNA), including Soman, Sarin, tabun or VX for instance. ${ }^{8}$ Contrary to popular belief and a misleading appellation, mustards and OPNA are not gaseous: they are liquid at atmospheric pressure ( $c a 140-220^{\circ} \mathrm{C}$ boiling point) but are mostly weaponized as sprays, explaining appellations such as " mustard gas ",... However, most CWA are toxic (or even lethal) by inhalation as well as by skin contact (Table 1) and some of them, such as Sarin, even have 
vapour pressure high enough to form a lethal gaseous phase in closed environments.
(1)<smiles>O=P(F)([Hg])O[AlH2]</smiles>

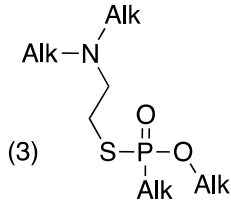

(and corresponding salts)
(4)

$$
\sim \sim \mathrm{Cl}
$$

(5)<smiles>CC(=CCl)C(C)Cl</smiles>
$n=1,2,3$

(7)

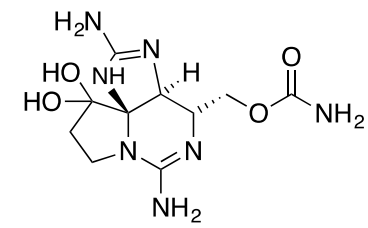

(6)

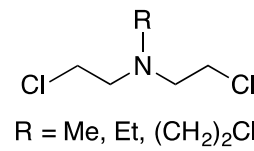

(8)

ricin

Scheme 1. Schedule 1 - Subdivison A (toxic chemicals) of the Chemical Weapons Convention: (1)-(2) G-Series organophosphorous (OP) nerve agents, (3) V-Series OP nerve agents, (4) Sulfur mustards, (5) Lewisites, (6) Nitrogen mustards, (7) Saxitoxin, (8) Ricin (glycoprotein).

Mustards are mostly incapacitating agents and only cause death on short-term by heavy inhalation and asphyxiation. ${ }^{9}$ In contact with skin, these highly electrophilic compounds bind to the proteins that ensure adhesion between skin layers, causing the formation of large and extremely painful blisters. Moreover, mustards alkylate DNA and its derivatives, and are therefore very carcinogenic and cytotoxic. These blistering/carcinogenic agents are relatively easy to synthesize on a "small" scale $(<100 \mathrm{~kg})$ and are a serious source of concern in the current terrorist context. The most representative member of this family is yperite (bis(2chloroethyl sulfide)), commonly named "mustard gas" although this nickname comes from the smell emitted by impurities stemming from some old synthesis processes. OPNA are much more toxic and very small quantities are lethal: a single drop of the most potent $\mathrm{VX}$ agent can cause the rapid death of a human being. They act by irreversibly inhibiting the acetylcholinesterase enzyme (AChE), preventing the return to rest of the nervous and muscular systems, with fatal cardiac and respiratory consequences. Moreover, they easily cross the

blood-brain barrier and cause severe brain damages in the unlikely event of survival. ${ }^{10,11}$

\subsection{Simulants of blistering and nerve agents}

The legislation on the acquisition/holding/use of CWA being very restrictive for security issues, and their toxicity requiring the use of equipments only available in military premises, studies are generally carried out on simulants (ersatz). Finding data common to all CWA is not trivial: Table 1 provides some relevant and comparable toxicity data for the main CWA, and also displays the main simulants used in decontamination studies and their correspondence with real agents. ${ }^{12}$

Regarding yperite, chloroethyl CEES is widely used and recognized as its most relevant simulant: its half-mustard structure induces the same polymerization behaviour as live agent under aqueous conditions (vide supra). ${ }^{12-14}$ Conversely, the profile for suitable OPNA mimics is not clear-cut since it is very difficult to keep reactivity without maintaining the acute toxicity. Organophosphonates DCNP (diethyl cyanophosphonate) and DFP (diisopropylfluorophosphate) have been regarded, for a long time, as analogues of choice for G-series agents, ${ }^{12,15}$ and phosphonates NIMP/NEMP (isopropyl-or ethyl- nitrophenyl methyl phosphonate) have gained in popularity due to UV analysis possibility. ${ }^{16}$ Experiments with convincing simulants of $V X$ poses a major problem as there is currently no commercially available molecule mimicking the $-\mathrm{S}-\left(\mathrm{CH}_{2}\right)_{2}-\mathrm{N}(i-\mathrm{Pr})_{2}$ key-motif involved in its bio-activity (this side chain simulating acetylcholine). In this sense, the phosphonothioate LG $61^{17}$ is rather unsatisfying, whereas phosphorothioates Demeton- $\mathrm{S}^{18}$ (and its methoxy analogue Demeton-S-methyl) and Tetriso ${ }^{19}$ have a closer structure to that of the live agent. Described in 2002 by Renard and Mioskowski, $\mathrm{PhX}$ is surely the closest alternative to $\mathrm{VX}{ }^{20}$ $\mathrm{PhX}$ differs only from $\mathrm{VX}$ by a phenyl in place of a non-reactive methyl group. This particularity therefore confers to $\mathrm{PhX}$ a reactivity close to that of $\mathrm{VX}$, which is essential for testing the selectivity of a neutralisation method. Despite its structural proximity with the real agent, this mimic has received little attention. It should also be noted that the phenyl appendage provides UV activity, and reduces the $\mathrm{IC}_{50}$ for AChE by a 60 -fold factor compared to $\mathrm{VX}$, classifying it out of international regulations. In addition, the one-day aging phenomenon (responsible for the irreversibility of the inhibition process) is negligible, which reduces the risks for the experimentalist. ${ }^{21}$ 


\section{ARTICLE}

Table 1. Toxicity of main CWA (yperite and nerve agents) and relevant simulants.

Common name ${ }^{[a]} \quad$ Toxicity $^{22} \quad$ Simulant

$\mathrm{LD}_{\mathrm{LO}}$

$\mathrm{LD}_{50}$

$\mathrm{LC}_{50}$

(human, skin) $(\mathrm{mg} / \mathrm{kg})^{[\mathrm{b}]} \quad$ (human, skin) $(\mathrm{mg} / \mathrm{kg})^{[\mathrm{c}]} \quad$ (mouse, inhalation) $\left(\mathrm{mg} / \mathrm{m}^{3}\right)^{[\mathrm{d}]}$

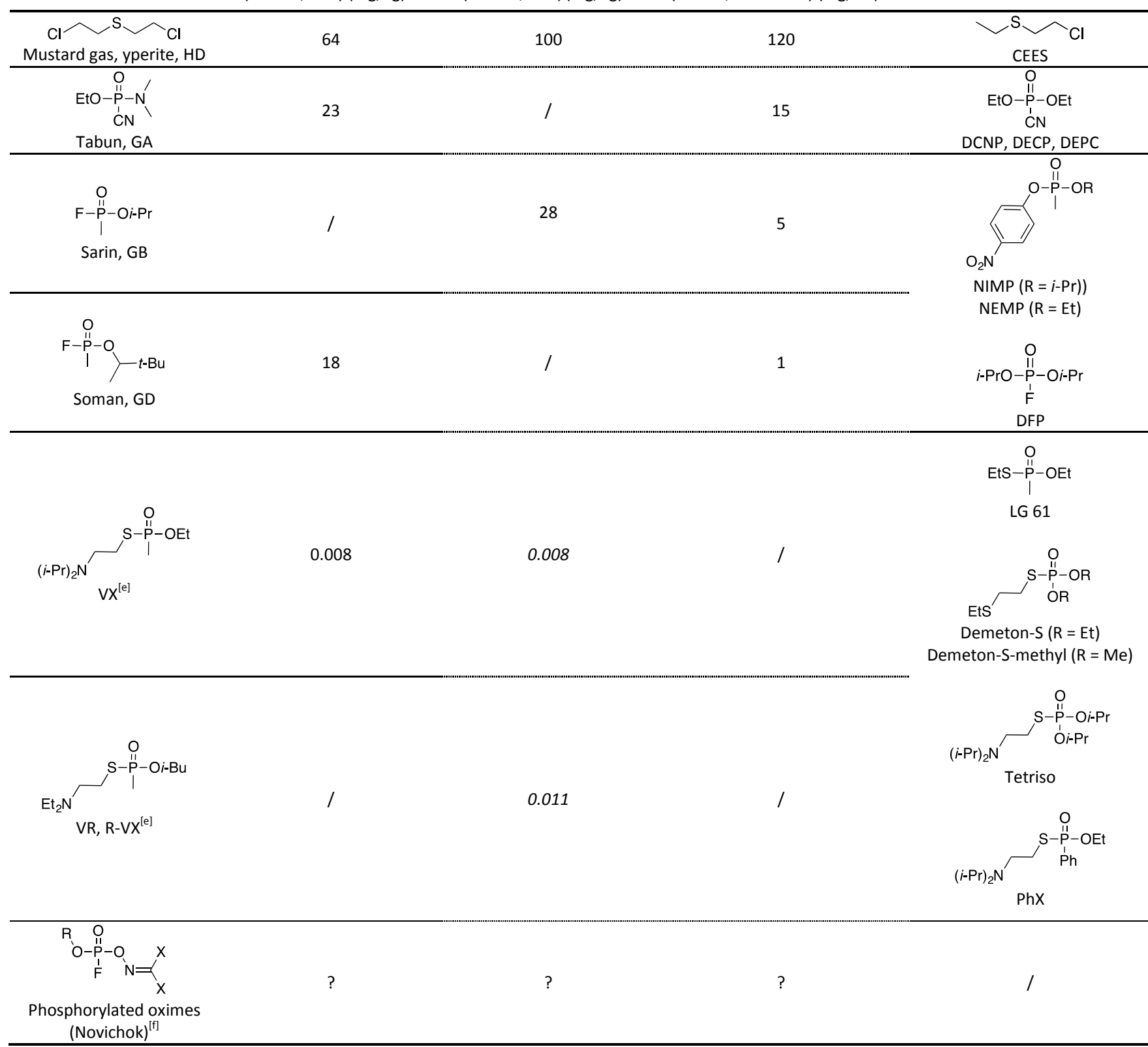

[a] HD stands for "hunstuff distilled"; GA, GB,... stand for "German". [b] Lowest lethal dose. [c] Median lethal dose. [d] Median lethal concentration in the air. [e] The only data available for VR is the $\mathrm{LD}_{50}$ (subcutaneous, guinea pig): $11 \mu \mathrm{g} / \mathrm{kg}$ vs $8 \mu \mathrm{g} / \mathrm{kg}$ for VX. [f] Chemical formula assumed from ref ${ }^{23}$. 


\section{Neutralisation methods}

There is a clear distinction between destruction and neutralisation of a CWA. The first method involves a one-step process allowing the full disposal of the toxic chemical, generally under extreme conditions, requiring specific heavy equipment on a dedicated site (typically pyrolysis). In contrast, neutralisation is a potentially reversible chemical treatment (ie leading to a possible precursor of (WA) but occurs under much less drastic conditions. ${ }^{24}$ Numerous neutralisation methods have been reported so far including solvolysis under basic conditions (alcohol, water) possibly with the assistance of biocatalysts (enzymes, antibodies). ${ }^{25}$ Dehydrohalogenation has also been specifically developed for mustard-type agents. ${ }^{25}$ Overall, hydrolysis and oxidation are the most efficient and employed chemical methods for the neutralisation of all kind of CWA.

\subsection{Hydrolysis}

The hydrolysis of OPNA from the G-series gives good results with the introduction of at least one hydroxyl function $(\mathrm{OH})$ substituting the leaving group (LG), $-\mathrm{CN}$ or $-\mathrm{F}$, and thus neutralisation of the compound toxicity (Scheme 2). Expectedly, this path is much less effective for V-series agents, which have been precisely designed to resist hydrolysis, by introducing the thioamino chain. This deceptively simple transformation also suffers from many pitfalls with mustard agents. Thus, yperite which is poorly soluble in water, reacts very slowly and does not afford thiodiglycol (TDG) as expected. Instead, it undergoes partial oligomerization/hydrolysis, rearranging into micelles that still contain important quantities of unaltered yperite in their core (Scheme 2$){ }^{14,26}$ this direct route is therefore little used for mustard agents. Hydrolysis under harsh conditions (high temperature, strongly basic aqueous medium) is able to detoxify some CWA as illustrated by the neutralisation of the declared Syrian stockpiles of Sarin (300 tons) and yperite (> 1000 tons) with the Field Deployable Hydrolysis System (FHDS) embarked on the Cape Ray ship. One of the major drawbacks of this system is the quantity of effluents released: 10-100 liters of polluted water/liter of CWA neutralised, the subsequent treatment of water being more expensive than the neutralisation itself. To address this concern, high efficiency and cleaner process are needed. Those could take the form of catalytic and/or environmentalfriendly reactions able to achieve high yield and selectivity for non-toxic products at higher reaction rates.
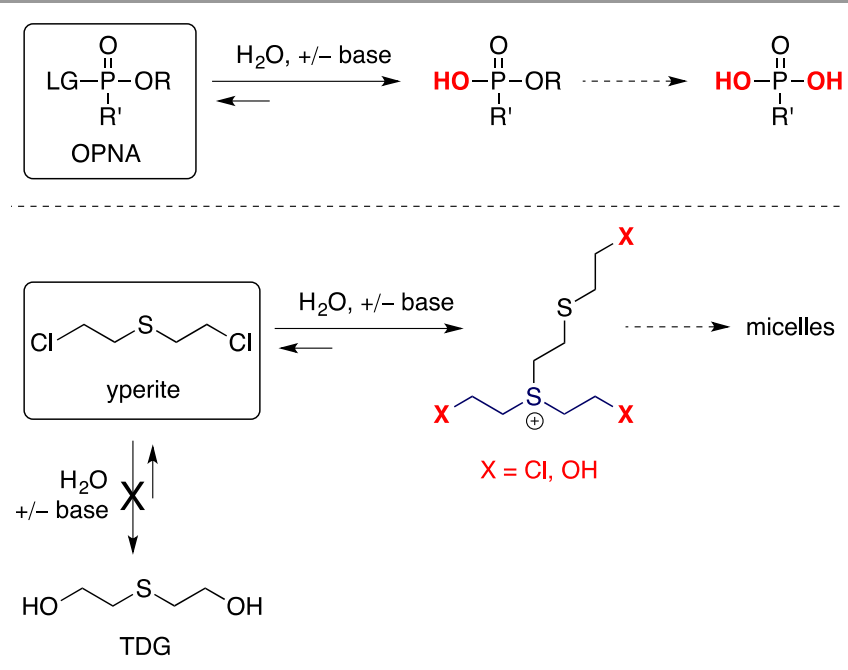

Scheme 2. Hydrolysis path for OPNA and yperite.

Immobilized organocatalysts. Hatton reported that hydrolysis of nerve agents could be catalysed by materials modified by strong nucleophiles, oximes and aminopyridines. ${ }^{27-30}$ Pralidoxime (2-PAM) is a classical antidote for nerve agent poisoning which acts by disconnecting the nerve agent from AChE by nucleophilic substitution. Thus, magnetite nanoparticles (M) modified by pralidoxime itself (PAM/M), or by oximes immobilized on polymeric materials (PVPOx-AA/M), allowed catalytic hydrolysis of DFP at neutral $\mathrm{pH}$ and could be recovered by magnetic separation and reused without loss in activity (Scheme 3$)^{28}$ The safety and high availability of magnetite and oximes, the simplicity of their combination, and the ease of particles recovery by magnetic separation offer a new technology for the hydrolysis of organophosphorus compounds under mild conditions. ${ }^{28,29}$

Later on, the same authors reported that water- and solvent-soluble nucleophilic polymers were able to catalyse the hydrolytic degradation of CWA. Whereas 4-pyridine aldoxime-modified polyvinylamine (PVAm-Ox) gave satisfactory results, polyvinylamine modified by 4aminopyridine (PVAm-APy) was the most effective to neutralise Soman as well as the most persistent $V X$ and yperite (Scheme 3). ${ }^{27,31}$ The half-life of Soman in aqueous PVAm-APy (suspension or gel) was estimated to $12 \mathrm{~min}$ at $\mathrm{pH} \mathrm{8.5,} \mathrm{and}$ addition of $\mathrm{VX}$ into $3.5 \mathrm{wt} \%$ suspensions of the supported catalyst in DMSO and $\mathrm{H}_{2} \mathrm{O}$ resulted in full degradation within $20 \mathrm{~min}$. Regarding hydrolysis of yperite, the mechanism is not fully understood and seems strongly dependent on reaction conditions: PVAm-APy gel facilitated the dehydrochlorination reaction of sulfur mustard into non-toxic divinylsulfide in a few hours, with catalyst poisoning as a consequence (Scheme 3 ), 
giving a biphasic shape to the kinetic plot of hydrolysis. Indeed when the amount of water and the mass transfer were too low to dissociate the ammonium salts, the number of nucleophilic catalytic sites of the PVAm-APy decreases, decreasing the reaction rates. These soluble polymers in aqueous phase allow, at reasonable catalytic charges $(<10 \%)$, degradation of OPNA and mustard agents in hours. The ability of these aminopyridine-modified materials to decompose the two persistent CWA VX and yperite, are promising for applications such as decontaminating CBRN protective clothing.

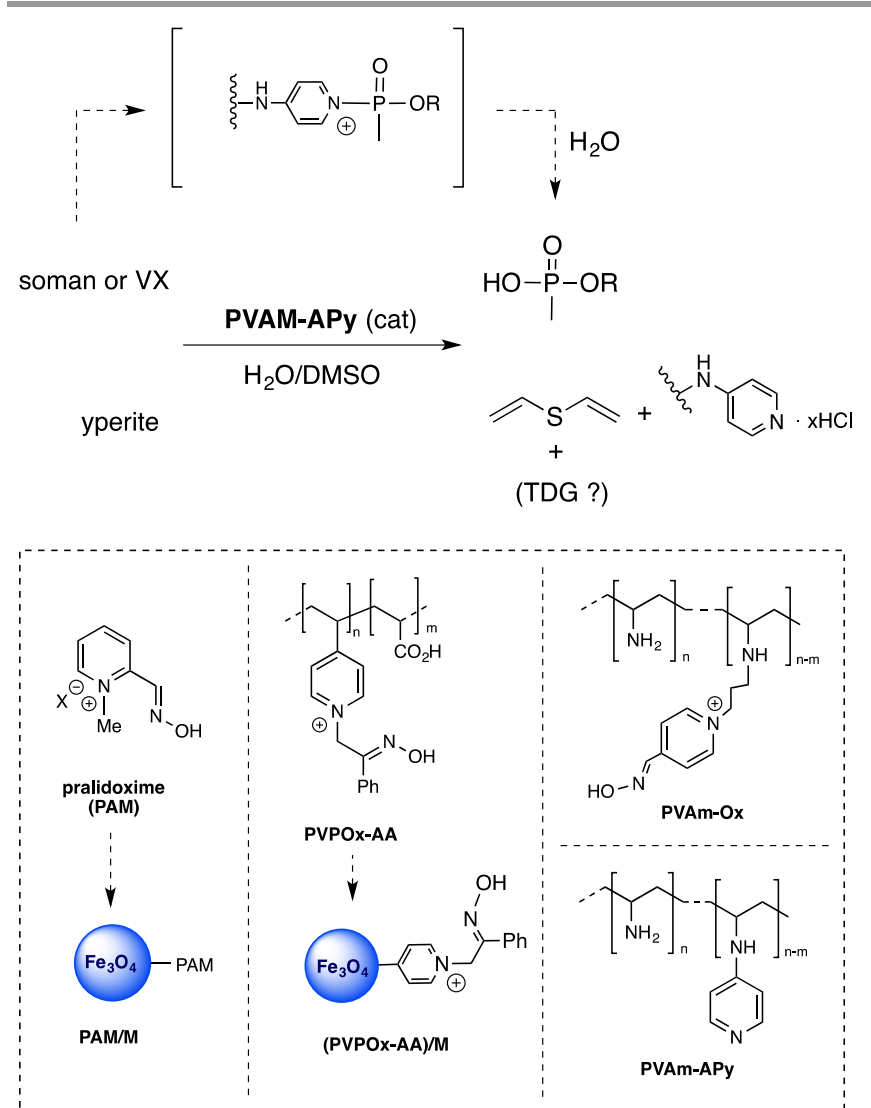

Scheme 3. Decomposition of $V X$ and CEES catalysed by supported nucleophilic organocatalysts.

Nanotubes. VX, Soman, and yperite undergo hydrolysis on the surface of titanium oxide nanotubes. ${ }^{32}$ The decomposition reaction of $V X$ being particularly fast $\left(t_{1 / 2}<30 \mathrm{~min}\right)$, approaching the conversions reached with conventional liquid decontaminants. Analyses reveal that $V X$ is adsorbed in the nanotubes. The hydrolysis of the more reactive Soman is unsurprisingly equally effective. In both cases, the hydrolysates attack the titanium structure to form a titanophosphonate species. Yperite is also hydrolysed into a sulfonium ion, dimer of thiodiglycol (see Scheme 2). ${ }^{32}$

Metal-organic frameworks (MOF). In recent years, metalorganic frameworks have shown their effectiveness for the decomposition of CWA by catalytic hydrolysis. ${ }^{33-36}$ If the issue of the thermal stability of MOF has been tackled long ago, strategies to stabilize MOF toward hydrolysis have only been explored in recent years. In particular, the introduction of hydrophobic molecule linkers into the networks and post- synthetic modifications have proved remarkably successful. Farha has identified different types of zirconium-clustercontaining MOF able to catalyse the hydrolysis of OPNA. Following the preliminary impressive results obtained in the degradation of the organophosphate paraoxon with MOF-808 and $\mathrm{UiO}-66,{ }^{37,38}$ the introduction of defects in the structure of UiO-66- $\mathrm{NH}_{2}$ (missing linker and node defects) significantly improved the decomposition. Best results in the degradation were obtained with highest defect MOF: the yields after 40 min reached 88 and $50 \%$ for Soman and VX, respectively (Table 2 , entries 1 and 2). ${ }^{39}$ Whereas, full conversion was obtained for Soman after $100 \mathrm{~min}$, no data is provided for VX at longer reaction time. The relationship between structure and hydrolysis, and the role of amino functionalities showed that the proximity of amino groups near the node is important for effective chemical detoxification. ${ }^{40}$ Calculations excluded the possibility that amino groups act as Brønsted bases, and suggested rather that microsolvation around defect sites directs reactivity. This can serve as a cornerstone for designing more effective MOF catalysts for the destruction of nerve agents. However, Frenkel recently showed that most Zr-based MOF are likely to collapse or to be poisoned by organophosphorus compounds, which constitutes a drawback for large scale applications. ${ }^{41}$

Polyoxometalates (POM). The polyoxomolybdate $\mathrm{K}_{2} \mathrm{H}\left[\left(\mathrm{H}_{2} \mathrm{O}\right)_{4} \mathrm{M}\right]\left[\mathrm{AsMo}_{6} \mathrm{O}_{21}(\mathrm{Ala})(\mathrm{PHBA})_{2}\right] \cdot \mathrm{nH}_{2} \mathrm{O}$ (POM-1) proved to be very efficient at only $0.1 \%$ loading for the hydrolysis of DCNP with full conversion within $10 \mathrm{~min}$ (Table 2, entry 3), ${ }^{42}$ far superior to polyoxoniobates $\left[\mathrm{C}_{n} \mathrm{H}_{2 \mathrm{n}+1} \mathrm{~N}\left(\mathrm{CH}_{3}\right)_{3}\right]_{7} \mathrm{HNb}_{6} \mathrm{O}_{19}$ $(\mathrm{POM}-2)^{43}$ and to the above-mentioned MOF for this tabun simulant (Table 2, entries 4-6). ${ }^{42}$ Moreover, POM-1 can be easily recovered by filtration and reused with full retention of activity. Only the one-dimensional polymeric polyniobate ( $\mathrm{P}$ $\mathrm{PONb}), \mathrm{K}_{12}\left[\mathrm{Ti}_{2} \mathrm{O}_{2}\right]\left[\mathrm{GeNb}_{12} \mathrm{O}_{40}\right] \cdot 19 \mathrm{H}_{2} \mathrm{O}$ (KGeNb) afforded full hydrolysis in a reasonable time lapse (30 min, entry 7). ${ }^{44}$ Moreover, KGeNb was also efficient for breaking down yperite. $^{44}$

Table 2. MOF- and POM-catalysed hydrolysis of organophosphorus nerve agents (OPNA)

\begin{tabular}{ccccc} 
Entry & OPNA & MOF & Time (min) & $\begin{array}{c}\text { Conversion } \\
(\%)\end{array}$ \\
\hline $1^{39}$ & Soman & MOF UiO-66-NH & 40 & $88^{[\mathrm{a}]}$ \\
\hline $2^{39}$ & $\mathrm{VX}$ & POM-1 & 10 & 50 \\
\hdashline $3^{42}$ & & POM-2 & $>120$ & 96 \\
$4^{43}$ & & UiO-66 & 30 & 99 \\
$5^{42}$ & DCNP & MOF-808 & 30 & 32 \\
$6^{42}$ & & KGeNb & 30 & 50 \\
$7^{44}$ & & & & 100
\end{tabular}

[a] Full conversion was attained after $100 \mathrm{~min}$.

\subsection{Oxidation}

Oxidation is a very popular way to neutralise CWA. Indeed, several easily accessible oxidants (e.g. hydrogen peroxide, hypochlorite salts, or even elemental oxygen) are able to perform this task. In the case of contamination of an 
infrastructure by CWA (floor/walls of a building, public transportation, ...), response teams proceed by spraying oxidants of various composition/formulation (liquids or foams generally). Nevertheless, these systems are not ideal nor very selective (vide infra). Indeed, if foams are easily recovered after use, they hardly penetrate porous materials (cement for example); liquid solutions penetrate surfaces but are not easy to remove, and generate considerable volumes of effluents which must be treated at exorbitant costs. Although oxidants have been reported to efficiently neutralise both OPNA and yperite, the decomposition path differs according to the CWA, which implies that the type of oxidant must be finely tuned according to the situation (Scheme 4).
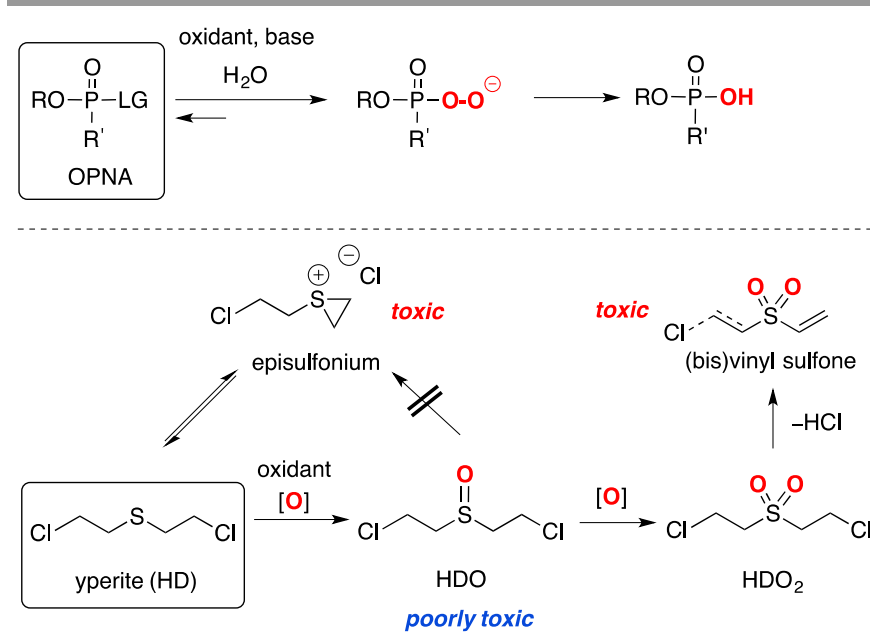

Scheme 4. Oxidative neutralisation path for OPNA and yperite.

Under basic conditions, hydrogen peroxide provides the perhydroxyl anion $\mathrm{HOO}^{-}$, a much stronger nucleophile than simple water or than the hydroxyl ion $\mathrm{HO}^{-}$. Perhydroxyl anion thus neutralises OPNA via perhydrolysis more effectively than conventional hydrolysis (Scheme 4). ${ }^{24}$ On another hand, photocatalytic materials based on titanium oxide nanotubes have proved efficient for the decomposition of the OPNA simulant dimethyl methyl phosphonate (DMMP) under simple solar irradiation. ${ }^{45,46}$ The decomposition path is suggested to involve radical hydroxyls affording methyl methylphosphonate (MMP) and methylphosphonic acid (MPA, Scheme 5).

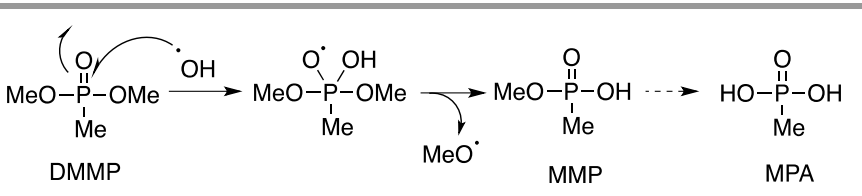

Scheme 5. Photocatalytic degradation of DMMP with $\mathrm{TiO}_{2}$ nanotubes.

The toxicity of mustards being related to their very electrophilic character due to the anchimeric assistance of the sulfur atom (formation of an episulfonium ion), their neutralisation goes through a deactivation of this electronic assistance. Thus, sulfur mustards are effectively neutralised by oxidation with various oxidants to obtain the corresponding sulfoxide (HDO). The selectivity of the reaction is essential because overoxidation leads to the sulfone, which undergoes fast $\mathrm{HCl}$ elimination to afford a bis(vinyl) sulfone, the latter being just as electrophilic and therefore as toxic- as the episulfonium ion (Scheme 4). Moreover the lipophilic character of yperite renders very difficult its oxidation with aqueous oxidants, such as $\mathrm{H}_{2} \mathrm{O}_{2}$ and $\mathrm{ClOK}$, and microemulsions constitute an efficient medium for the common neutralisation of OPNA and mustard agent. ${ }^{47}$ Interestingly, Wagner used tetraperoxomolybdate generated from $\mathrm{K}_{2} \mathrm{MoO}_{4}$ /aq. $\mathrm{H}_{2} \mathrm{O}_{2}$ in the presence of surfactants, for a neutralisation of VX, Soman and yperite, but accompanied by the overoxidation product $\mathrm{HDO}_{2}{ }^{48}$ More recent research with supported catalytic systems for the oxidation of the yperite simulant CEES to inert sulfoxide CEESO has been reported in organic solvents (Table 3).

\begin{tabular}{|c|c|c|c|c|}
\hline \multicolumn{2}{|c|}{ CEES } & SO & $\mathrm{CEESO}_{2}$ & \multirow{2}{*}{$\begin{array}{l}\text { VESO } \\
\begin{array}{l}\text { Selectivity for } \\
\text { CEESO (by- } \\
\text { product) }\end{array} \\
\text { (II }\end{array}$} \\
\hline Entry & Catalyst & Oxidant & $\begin{array}{l}\text { Time } \\
(\min )^{[a]}\end{array}$ & \\
\hline $1^{49}$ & $\begin{array}{l}\text { V-doped } \\
\text { mesoporous silica }\end{array}$ & EtCHO/air & 45 & $\begin{array}{l}70 \% \\
\left(\mathrm{CEESO}_{2}\right)\end{array}$ \\
\hline $2^{50}$ & $\mathrm{Nb}-\mathrm{SAP}$ & $30 \%$ aq. $\mathrm{H}_{2} \mathrm{O}_{2}$ & 420 & $\begin{array}{l}66 \% \\
\left(\mathrm{CEESO}_{2}\right)\end{array}$ \\
\hline $3^{51}$ & PCN-222/MOF-545 & $\begin{array}{l}\mathrm{O}_{2} \text { blue-LED } \\
\text { irradiation) }\end{array}$ & 20 & $>99 \%$ \\
\hline $4^{52}$ & TBTD/MOF-UiO-68 & $\begin{array}{l}\text { air (blue-LED } \\
\text { irradiation) }\end{array}$ & 10 & $>99 \%$ \\
\hline $5^{42}$ & POM-1 & $\mathrm{H}_{2} \mathrm{O}_{2}^{[b]}$ & 5 & $>99 \%$ \\
\hline $6^{43}$ & POM-2 & $3 \%$ aq. $\mathrm{H}_{2} \mathrm{O}_{2}$ & 20 & $98 \%$ \\
\hline $7^{53}$ & POM-3 & $3 \%$ aq. $\mathrm{H}_{2} \mathrm{O}_{2}$ & 3 & $75 \%$ (VESO) \\
\hline $8^{54}$ & FC-TPE-CMP & $\begin{array}{l}\mathrm{O}_{2} / \text { simulated } \\
\text { solar light }\end{array}$ & 75 & $>99 \%$ \\
\hline
\end{tabular}

[a] Time for full consumption of CEES. [b] $\mathrm{H}_{2} \mathrm{O}_{2}$ concentration was not given.

CEES can be oxidized under ambient conditions using excess propionaldehyde and air, in the presence of a heterogeneous vanadium catalyst on mesoporous silica. The peracid $\mathrm{EtCO}_{3} \mathrm{H}$ is generated in situ and oxidizes in turn CEES and CEESO. Nevertheless, significant amounts of toxic $\mathrm{CEESO}_{2}$ sulfone are generated before the CEES is fully converted to CEESO and a 0:66:34 ratio of CEES/CEESO/CEESO ${ }_{2}$ was attained after $45 \mathrm{~min}$ at best (Entry 1). If the reaction was left for 75 min, the sulfone was the only product remaining. Attractively, this protocol is run in methoxyperfluorobutane (HFE-7100), a nonflammable and innocuous hemifluorinated ether. 
Moreover HFE-7100 can be used to wash contaminated polymeric and electronic materials without causing any damage. ${ }^{49}$ Similar results were attained with niobium(V) inserted into saponite clay (Nb-SAP). In the presence of $30 \%$ aqueous $\mathrm{H}_{2} \mathrm{O}_{2}$, the CEES (in heptane) is completely decomposed in 9 min in CEESO (66\%) accompanied by $\mathrm{CEESO}_{2}$ (34\% ; Entry 2). ${ }^{50}$

Interestingly, MOF and POM catalysts which were efficient for hydrolysis of OPNA, also proved highly effective for selective sulfoxidation of CEES. ${ }^{55}$ The most spectacular results were obtained with MOF including porphyrin-photosensitizers as linkers, allowing generation of singlet oxygen ${ }^{1} \mathrm{O}_{2}$ under blue-light emitting diode (LED) irradiation in methanol. Farha and Hupp reported the complete conversion into CEESO in 20 min with PCN-222/MOF-545 and $\mathrm{O}_{2}$ (entry 3). ${ }^{51}$ Impressively, no toxic sulfone was detected during the reaction course. Equally impressive results were later reported by Wang who described a photoactive triazolobenzothiadiazole-moietyfunctionalized MOF (TBTD/UiO-68) for the photocatalysed full and selective oxidation of CEES into CEESO within only $10 \mathrm{~min}$ under simple air atmosphere (entry 4). ${ }^{52}$ Polyoxometalates POM-1 and -2 are also very versatile for fast decontamination with hydrogen peroxide as primary oxidant within 5 and 20 min respectively (entries 5 and 6). ${ }^{42,43}$ A polyoxometallate complex based on polyoxoniobate and polyoxovanadate (POM-3) in the presence of $3 \%$ aqueous $\mathrm{H}_{2} \mathrm{O}_{2}$ allows the complete oxidative decontamination of CEESO in only $3 \mathrm{~min}$, however accompanied by the dehydrochlorinated sulfoxide VESO of unknown toxicity (Entry 7). ${ }^{53} \mathrm{~A}$ very interesting results has just been reported with ferrocene-based conjugated microporous polymers (Fc-CMPs). Among them, a methanolic solution of Fc-TPE-CMP (TPE = tetrakis(4ethynylphenyl)ethene) is able to generate reactive oxygen species $\left({ }^{\circ} \mathrm{O}_{2}^{-}, \mathrm{H}_{2} \mathrm{O}_{2},{ }^{\circ} \mathrm{OH},{ }^{1} \mathrm{O}_{2}\right)$ under simulated solar light and oxygen atmosphere. By this mean, CEES is fully converted into CEESO with full selectivity and Fc-TPE-CMP can be reused for five runs without loss in efficiency. ${ }^{54}$

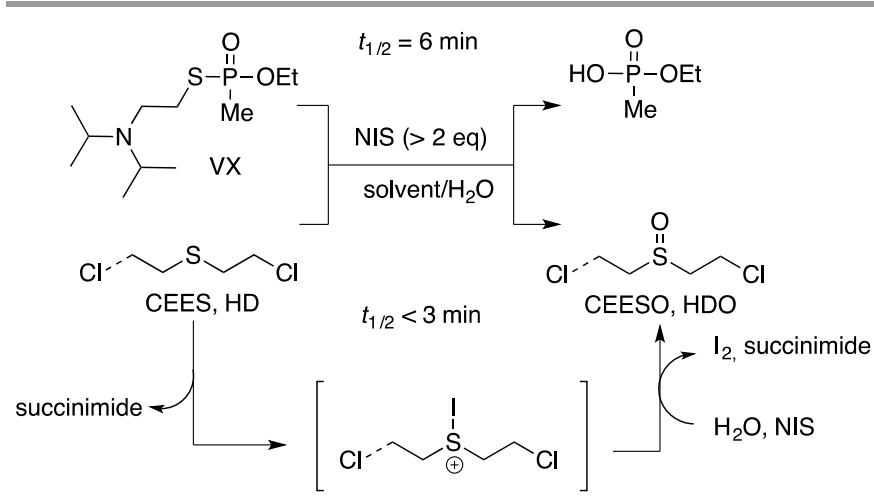

Scheme 6. Oxidative neutralisation of CEES and yperite with NIS.

Very recently, an original oxidative path involving $\mathrm{N}$ iodosuccinimide (NIS) and water as oxygen donor has been reported by an Israeli group. The reaction is fast $\left(t_{1 / 2}<3 \mathrm{~min}\right)$ and proceeds through an iodosulfonium species, the iodine atom being further displaced by water. The released iodide then reacts with NIS to afford molecular iodine and succinimide (Scheme 5, down). This reaction is very effective with CEES as well as with yperite, but requires large quantities of NIS (2-4 eq). Interestingly, the combination NIS/water is also able to break down VX into innocuous monoethyl methylphosphonate but probably through a different mechanism involving a iodoammonium intermediate rather than a iodosulfonium (Scheme 6 , up). ${ }^{17}$

It is important to note that the amounts of decontaminated CWA, or simulants, by all these catalytic methods are usually very low (10-100 $\mathrm{mg}$ ); these promising strategies are currently only at the proof of concept level and moving up to a realistic neutralisation scale of several grams still seems far off. Regarding process intensification (scale-up), continuous flow technology is undoubtedly a major advance of the last decade. ${ }^{56,57}$ The specific sizing of flow microreactors notably allows a perfect reaction control with excellent mass and heat transfers. In addition, their reduced dimensions make them ideal for the design of portable devices, and their modularity enables different setup according to specific needs. In this context, a continuous flow system was set up to neutralise $25 \mathrm{~g}$ of CEES, within $45 \mathrm{~min}$, by means of an acidic alcoholic solution of the user-friendly oxidant urea- $\mathrm{H}_{2} \mathrm{O}_{2}$ complex (UHP). ${ }^{58}$ This device exhibits several salient features: i) complete consumption of the mustard simulant with a selectivity $>99 \%$ within $2 \mathrm{~min}$ in the microreactor (internal diameter $=1.6 \mathrm{~mm}$ ), ii) contact between the operator and the chemicals is limited since CEES and the oxidizing solution are pumped by introducing a PFA tube into each respective bottle; the two solutions then mix in a T-mixer and the reaction occurs within a $15 \mathrm{~m}$ reactor tube whose outlet flows into a reducing solution to quench the reaction at the CEESO stage. iii) The reaction progress can be monitored with an in-line benchtop NMR spectrometer, allowing a real-time manual adjustment of reaction conditions (Scheme 7). ${ }^{58,59}$

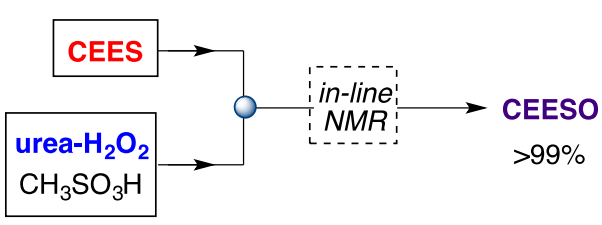

$25 \mathrm{~g}$ neutralised in $45 \mathrm{~min}\left(t^{R}=2 \mathrm{~min}\right)$

Scheme 7. Flow system for the neutralisation of CEES with inline NMR.

It is worth noting that it is important to use tubing reactor with internal diameter $>1.2 \mathrm{~mm}$ (milli- or even meso-fluidic) to avoid clogging issues which could trigger dramatic consequences with such toxic chemicals.

\section{Conclusions}

Despite international prohibition, the threat of chemical weapons is unfortunately still pending. It is therefore of prime importance to intensify efforts toward universal decontamination methods able to neutralise various types of CWA (nerve or blistering agents) under several forms (mostly liquid in keg/shells or spilled, ... but also powders) while deployable on any field. In addition, realistic and handy 
methods will have to produce as little and benign effluent as possible. Hydrolysis or oxidation by aqueous solutions have proved to be successful but the quantity of polluted water generated is considerable and requires very costly treatments. As such, resorting to processes limiting effluent volumes - and possibly water volumes - will soon become an imperious objective. Hence alcoholic neutralising solutions (ethanol ideally), which can subsequently be incinerated, offer interesting approaches. While the use of photocatalysedprocesses, MOF and POM catalysts give very brilliant results, those methods are currently viable at milligrams scale at the moment and cannot easily be transposed to live cases yet. In this regard, the use of portable devices based on continuous flow reactors, capable of treating in the same way a few milligrams as a few tens of grams, seems promising for future developments but is limited to pumpable material. Due to the inherent shortcomings of each method, those should rather be considered as complementary alternatives until further progresses toward universal and sustainable methods of neutralisation are achieved.

\section{Conflicts of interest}

There are no conflicts to declare.

\section{Acknowledgements}

Financial support from Labex SynOrg (ANR-11-LABX-0029), University of Rouen Normandy, INSA Rouen Normandy, CNRS (programmes "Attentats-recherche" and "Sécurité des sociétés et des systèmes"), and Région Normandie (CRUNCh network) and the European INTERREG $\vee$ A France (Channel)-England Cross-border Cooperation Programme LabFact, co-financed by ERDF, is acknowledged.

\section{Notes and references}

1 B. Hautecouverture, Fondation Pour la Recherche Stratégique, 2018, Note 02/18.

2 Organisation for the Prohibition of Chemical Weapons, Articles, https://www.opcw.org/chemical-weapons-convention/articles, (accessed November 26, 2018).

3 S. J. S. Flora, in Handbook of Arsenic Toxicology, Elsevier, 2015, pp. 1-49.

4 J. A. Galvão, M. Oetterer, M. do C. Bittencourt-Oliveira, S.

Gouvêa-Barros, S. Hiller, K. Erler, B. Luckas, E. Pinto and P. Kujbida, Toxicon, 2009, 54, 891-894.

5 J. M. Lord and L. M. Roberts, in Microbial Protein Toxins, eds. M. J. Schmitt and R. Schaffrath, Springer Berlin Heidelberg, Berlin, Heidelberg, 2004, vol. 11, pp. 215-233.

6 D. C. Keyes, Ed., Medical response to terrorism: preparedness and clinical practice, Lippincott Williams \& Wilkins, Philadelphia, 2005.

7 R. N. Saladi, E. Smith and A. N. Persaud, Clin. Exp. Dermatol., 2006, 31, 1-5.

8 A. Vale, T. C. Marrs and P. Rice, Medicine (Baltimore), 2007, 35, 573-575.

9 K. Ghabili, P. S. Agutter, M. Ghanei, K. Ansarin, Y. Panahi and M.
M. Shoja, Crit. Rev. Toxicol., 2011, 41, 384-403.

10 H. Thiermann, F. Worek and K. Kehe, Chem. Biol. Interact., 2013, 206, 435-443.

11 F. Dorandeu and F. Nachon, Biofutur, 2017, 384, 42-45.

12 J. Lavoie, S. Srinivasan and R. Nagarajan, J. Hazard. Mater., 2011, 194, 85-91.

13 J. R. Hiscock, G. P. Bustone and E. R. Clark, ChemistryOpen, 2017, 6, 497-500.

14 S. Y. Bae and M. D. Winemiller, J. Org. Chem., 2013, 78, 64576470.

15 I. Candel, M. D. Marcos, R. Martínez-Máñez, F. Sancenón, A. M. Costero, M. Parra, S. Gil, C. Guillem, F. Pérez-Plá and P. Amorós, Microporous Mesoporous Mater., 2015, 217, 30-38.

16 E. C. Meek, H. W. Chambers, A. Coban, K. E. Funck, R. B. Pringle, M. K. Ross and J. E. Chambers, Toxicol. Sci., 2012, 126, 525-533.

17 B. Smolkin, N. Levi, N. Karton-Lifshin, L. Yehezkel, Y. Zafrani and I. Columbus, J. Org. Chem., 2018, 83, 13949-13955.

18 V. Vallet, C. Cruz, J. Licausi, A. Bazire, G. Lallement and I. Boudry, Toxicology, 2008, 246, 73-82.

19 Y. J. Rosenberg, J. Walker, X. Jiang, S. Donahue, J. Robosky, M. Sack, J. Lees and L. Urban, Sci. Rep., , DOI:10.1038/srep13247.

20 P.-Y. Renard, H. Schwebel, P. Vayron, L. Josien, A. Valleix and C. Mioskowski, Chem. - Eur. J., 2002, 8, 2910-2916.

21 P. Vayron, University Paris South, 1999.

22 ChemIDplus Advanced - Chemical information with searchable synonyms, structures, and formulas,

https://chem.nlm.nih.gov/chemidplus/, (accessed November 26, 2018).

23 M. Peplow, Chem. Eng. News, 2018, 96, 3.

24 Y. J. Jang, K. Kim, O. G. Tsay, D. A. Atwood and D. G. Churchill, Chem. Rev., 2015, 115, PR1-PR76.

25 B. M. Smith, Chem. Soc. Rev., 2008, 37, 470-478.

26 C. A. S. Brevett, K. B. Sumpter and R. G. Nickol, J. Hazard.

Mater., 2009, 162, 281-291.

27 L. Bromberg, W. R. Creasy, D. J. McGarvey, E. Wilusz and T. A. Hatton, ACS Appl. Mater. Interfaces, 2015, 7, 22001-22011.

28 L. Bromberg and T. A. Hatton, Ind. Eng. Chem. Res., 2005, 44 7991-7998.

29 L. Bromberg and T. A. Hatton, Ind. Eng. Chem. Res., 2007, 46, 3296-3303.

30 L. Bromberg, H. Schreuder-Gibson, W. R. Creasy, D. J.

McGarvey, R. A. Fry and T. A. Hatton, Ind. Eng. Chem. Res., 2009, 48, 1650-1659.

31 see also:, R. S. Mello, E. S. Orth, W. Loh, H. D. Fiedler and F. Nome, Langmuir, 2011, 27, 15112-15119.

32 G. W. Wagner, Q. Chen and Y. Wu, J. Phys. Chem. C, 2008, 112, 11901-11906.

33 S. S. Mondal and H.-J. Holdt, Angew. Chem. Int. Ed., 2016, 55, 42-44.

34 Y. Liu, A. J. Howarth, N. A. Vermeulen, S.-Y. Moon, J. T. Hupp and O. K. Farha, Coord. Chem. Rev., 2017, 346, 101-111.

35 K. Vellingiri, L. Philip and K.-H. Kim, Coord. Chem. Rev., 2017, 353, 159-179.

36 J. E. Mondloch, M. J. Katz, W. C. Isley lii, P. Ghosh, P. Liao, W. Bury, G. W. Wagner, M. G. Hall, J. B. DeCoste, G. W. Peterson, R. Q. Snurr, C. J. Cramer, J. T. Hupp and O. K. Farha, Nat. Mater., 2015, 14, 512-516.

37 M. J. Katz, J. E. Mondloch, R. K. Totten, J. K. Park, S. T. Nguyen, O. K. Farha and J. T. Hupp, Angew. Chem. Int. Ed., 2014, 53, 497501.

38 S.-Y. Moon, Y. Liu, J. T. Hupp and O. K. Farha, Angew. Chem. Int. Ed., 2015, 54, 6795-6799. 
39 G. Peterson, M. Destefano, S. Garibay, A. Ploskonka, M.

McEntee, M. Hall, C. Karwacki, O. Farha and J. Hupp, Chem. - Eur. J., 2017, 23, 15913-15916.

40 T. Islamoglu, M. A. Ortuño, E. Proussaloglou, A. J. Howarth, N. A. Vermeulen, A. Atilgan, A. M. Asiri, C. J. Cramer and O. K. Farha, Angew. Chem. Int. Ed., 2018, 57, 1949-1953.

41 A. M. Plonka, Q. Wang, W. O. Gordon, A. Balboa, D. Troya, W. Guo, C. H. Sharp, S. D. Senanayake, J. R. Morris, C. L. Hill and A. I. Frenkel, J. Am. Chem. Soc., 2017, 139, 599-602.

42 Y. Hou, H. An, Y. Zhang, T. Hu, W. Yang and S. Chang, ACS Catal., 2018, 8, 6062-6069.

43 X. Li, J. Dong, H. Liu, X. Sun, Y. Chi and C. Hu, J. Hazard. Mater., 2018, 344, 994-999.

44 W. Guo, H. Lv, K. P. Sullivan, W. O. Gordon, A. Balboa, G. W. Wagner, D. G. Musaev, J. Bacsa and C. L. Hill, Angew. Chem. Int. Ed., 2016, 55, 7403-7407.

45 M. Grandcolas, A. Louvet, N. Keller and V. Keller, Angew. Chem. Int. Ed., 2009, 48, 161-164.

46 M. Grandcolas, L. Sinault, F. Mosset, A. Louvet, N. Keller and V. Keller, Appl. Catal. Gen., 2011, 391, 455-467.

47 I. A. Fallis, P. C. Griffiths, T. Cosgrove, C. A. Dreiss, N. Govan, R. K. Heenan, I. Holden, R. L. Jenkins, S. J. Mitchell, S. Notman, J. A. Platts, J. Riches and T. Tatchell, J. Am. Chem. Soc., 2009, 131, 97469755.

48 G. W. Wagner, L. R. Procell, Y.-C. Yang and C. A. Bunton, Langmuir, 2001, 17, 4809-4811.

49 S. R. Livingston and C. C. Landry, J. Am. Chem. Soc., 2008, 130, 13214-13215.

50 F. Carniato, C. Bisio, R. Psaro, L. Marchese and M. Guidotti, Angew. Chem. Int. Ed., 2014, 53, 10095-10098.

51 Y. Liu, A. J. Howarth, J. T. Hupp and O. K. Farha, Angew. Chem. Int. Ed., 2015, 54, 9001-9005.

52 W.-Q. Zhang, K. Cheng, H. Zhang, Q.-Y. Li, Z. Ma, Z. Wang, J. Sheng, Y. Li, X. Zhao and X.-J. Wang, Inorg. Chem., 2018, 57, 42304233.

53 J. Dong, J. Hu, Y. Chi, Z. Lin, B. Zou, S. Yang, C. L. Hill and C. Hu, Angew. Chem. Int. Ed., 2017, 56, 4473-4477.

54 L. Ma, Y. Liu, Y. Liu, S. Jiang, P. Li, Y. Hao, P. Shao, A. Yin, X. Feng and B. Wang, Angew. Chem. Int. Ed., 2019, 58, 4221-4226.

55 Y. Liu, C. T. Buru, A. J. Howarth, J. J. Mahle, J. H. Buchanan, J. B. DeCoste, J. T. Hupp and O. K. Farha, J. Mater. Chem. A, 2016, 4, 13809-13813.

56 R. L. Hartman, J. P. McMullen and K. F. Jensen, Angew. Chem. Int. Ed., 2011, 50, 7502-7519.

57 R. Gérardy, N. Emmanuel, T. Toupy, V.-E. Kassin, N. N.

Tshibalonza, M. Schmitz and J.-C. M. Monbaliu, Eur. J. Org. Chem., 2018, 2018, 2301-2351.

58 B. Picard, B. Gouilleux, T. Lebleu, J. Maddaluno, I. Chataigner, M. Penhoat, F.-X. Felpin, P. Giraudeau and J. Legros, Angew. Chem. Int. Ed., 2017, 56, 7568-7572.

59 P. Giraudeau and F.-X. Felpin, React. Chem. Eng., 2018, 3, 399413. 